\title{
A Cadeia Produtiva da Maçã em São Joaquim-SC sob as Perspectivas: Embeddedness e Formação de Preços e Quantidades
}

Frederico Santos Damasceno Graduação em Ciências Econômicas pela Universidade Comunitária da Região de Chapecó - UNOCHAPECÓ Servidão Anjo da Guarda, 295-D. Efapi. Chapecó/SC. CEP: 89.809-900 E-mail: fredsantos1607@gmail.com

Fabio Piccinini Graduação em Ciências Econômicas pela Universidade Comunitária da Região de Chapecó - UNOCHAPECÓ Servidão Anjo da Guarda, 295-D. Efapi. Chapecó/SC. CEP: 89.809-900 E-mail: fabiojpiccinini@gmail.com Ângelo Brião Zanela
Doutorado em Desenvolvimento Econômico pela Universidade Federal do Paraná -
UFPR
Professor da Universidade Federal da Fronteira Sul - UFFS
Rodovia SC 484 Km 02. Bairro Fronteira Sul. Chapecó/SC. CEP: 89.809-000
E-mail: abzanela@yahoo.com.br

\section{RESUMO}

O conceito de "embeddedness" ganhou notoriedade nas ciências sociais. A amplitude desse conceito deixou evidente que tanto o mecanismo de preços, quanto a interação social de atores individuais e coletivos são fundamentais a realização das trocas de natureza econômica. Nesta perspectiva, o presente artigo apresentou a dimensão do "embeddedness" como ação precursora à produção de maçã em São Joaquim-SC concluindo que a evolução da cadeia produtiva da maçã, neste município, esta relacionada com os vínculos sócioculturais estabelecidos regionalmente, assim como, a variação dos preços, a qual passou a ser investigada diante do comportamento da série de tempo que revelou a presença de componentes de tendência e de sazonalidade. A partir daí optou-se por realizar previsões, utilizando-se os métodos de Holt-Winters aditivo e multiplicativo, baseados em três equações alisadoras: de nível, tendência e sazonalidade. Concluiu-se que a produção de maçã em São Joaquim está submersa nas realizações em âmbito institucional, nos valores, características e sabor próprio do produto regionalmente ofertado, valorizando-se assim, as características sociais desse mercado, mas que a variação de preços também explica como a produção de maçã consolida-se como atividade fundamental para o desenvolvimento de São Joaquim-SC.

Palavras-Chave: Cadeia Podutiva. Maçã. Embeddedness. Preços. São Joaquim-SC. 
A Cadeia Produtiva da Maçã em São Joaquim-SC sob as Perspectivas: Embeddedness e

Formação de Preços e Quantidades

Frederico Santos Damasceno, Fabio Piccinini, Ấngelo Brião Zanela

\section{ABSTRACT}

The concept of embeddedness has gained notoriety in the social sciences. The breadth of this concept made it clear that both the price mechanism and the social interaction of individual and collective actors are fundamental to the realization of economic exchanges. In this perspective, the present article presented the dimension of "embeddedness" as a precursor action to apple production in São Joaquim-SC, concluding that the evolution of the apple productive chain in this municipality is related to the regionally established socio-cultural bonds, as well as price variation, which was investigated in view of the behavior of the time series that revealed the presence of trend and seasonality components. From then on, it was decided to make predictions using the additive and multiplicative Holt-Winters methods based on three smoothing equations: level, trend and seasonality. It was concluded that apple production in São Joaquim is submerged in the institutional achievements, values, characteristics and own flavor of the regionally offered product, thus valuing the social characteristics of this market, but that the price variation also explains how apple production is consolidated as a fundamental activity for the development of São Joaquim-SC.

Keywords: Productive Chain. Apple. Embeddedness. Prices. São Joaquim-SC.

\section{INTRODUÇÃO}

São Joaquim é uma cidade brasileira do Estado de Santa Catarina, situada no planalto serrano com 24.812 habitantes, segundo dados do Censo de 2010 do Instituto Brasileiro de Geografia e Estatística (IBGE). Sua composição étnica é formada basicamente por descendentes de alemães, italianos, portugueses e japoneses. A atividade econômica do município está direcionada basicamente ao cultivo de frutas, em que a maçã é o grande destaque. A cadeia produtiva é formada por grandes empresas integradas verticalmente e, em menor volume, por um grande número de pequenos produtores. Merece ser destacado que é uma das atividades que mais recebe investimento em tecnologia e qualidade do país. Esta fruta além do consumo fresco é utilizada em diversos tipos de processamento gerando produtos como doces, compotas, bebidas (sucos e vinhos) e vinagres.

Para analisar a interação entre o comportamento dos agentes individuais e coletivos, bem como o sistema de produção e comércio diferenciados, levam-se em 
A Cadeia Produtiva da Maçã em São Joaquim-SC sob as Perspectivas: Embeddedness e Formação de Preços e Quantidades

Frederico Santos Damasceno, Fabio Piccinini, Ẩngelo Brião Zanela

consideração, neste trabalho, tanto os vínculos sócioculturais entre todos os participantes da cadeia produtiva, como a variação de preços e quantidades estabelecidos pelas características inerentes a esse mercado. As duas perspectivas deverão ser capazes de explicar a evolução da principal atividade econômica do município e os resultados em âmbito territorial. Com o propósito de promover aderência entre as proposições teóricas sintetizadas neste trabalho e a atividade econômica promovida pela cadeia produtiva da maçã em São Joaquim-SC, além desta Introdução, a seção 2 apresenta o referencial teórico, ressaltando as as origens conceituais de "embeddedness"; a seção três, por sua vez, trata da amplitude do respectivo conceito e sua importância nas diversas áreas de pesquisa, com ênfase à área de geografia econômica. Já na seção quatro, apresenta-se a sociologia dos mercados diante da produção de maçã no município de São Joaquim-SC. A secção cinco trata de apresentar a Cadeia produtiva da maçã em São Joaquim-SC sob a perspectiva de variações de preços e quantidade. Uma análise estará baseada nos métodos de HoltWinters aditivo e multiplicativo para previsão da quantidade negociada de maçã no respectivo município. Enquanto a seção seis trata das considerações finais e a seção sete apresenta as referências.

\section{REFERENCIAL TEÓRICO}

\subsection{Embeddedness: origens conceituais (de Polanyi à Granovetter)}

"Embeddedness" - que a partir de tradução livre pode ser definida sob alguns termos, entre eles: imersão, enraizamento, incrustação, imbricação ${ }^{1}$ - é um conceito popularizado a partir dos pensamentos de Karl Polanyi. Posteriormente, foi redesenhado por Mark Granovetter, com grande repercussão nas ciências sociais ${ }^{2}$ economia, sociologia, antropologia e geografia econômica.

\footnotetext{
${ }^{1}$ Segundo Hess (2004): "These terminologies need to be unraveled if we are to have a clearer picture of common ground and the substantive meanings of different concepts of embeddedness".

${ }^{2}$ Levando-se em consideração as diferenças nas concepções teóricas estabelecidas pelos dois autores.
} 
A Cadeia Produtiva da Maçã em São Joaquim-SC sob as Perspectivas: Embeddedness e Formação de Preços e Quantidades Frederico Santos Damasceno, Fabio Piccinini, Ẩngelo Brião Zanela

Para Swedberg e Granovetter (1992); Barber (1995); Hess (2004), Polanyi pode ser considerado o pai do conceito de "embeddedness". Durante a Segunda Guerra Mundial, o pensador austríaco de origem judia, escreveu sua obra com o objetivo de tentar desvendar os princípios políticos e econômicos de uma época intitulada: "A Grande Transformação (1944)". Havia no pensamento de Polanyi uma forte insatisfação com a idolatria superdimensionada atribuída ao mercado - a absolutização do mercado - e com a lógica da autorregulação a ele conferida. Para Polanyi (2000), em períodos pré-capitalistas, as economias estavam inseridas na sociedade e em seus fundamentos sociais e culturais. Em economias de mercados modernos, as relações sociais e culturais é que foram inseridas no sistema econômico ${ }^{3}$. Nas palavras de Hess (2004), Polanyi acreditava que: "ao contrário das sociedades anteriores, os elementos culturais e sociais se tornaram economizados e monetizados. Assim, o trabalho passa a ser considerado como uma mercadoria e o princípio do "homo economicus" prevalece e domina a sociedade moderna".

Em "A Grande Transformação", Polanyi elucidou que a Revolução Industrial, o comércio marítimo e o progresso, peculiares à Inglaterra do século XIX, afetaram a vida e o bem-estar daquela sociedade, o que por sua vez definiu o conceito de (des) enraizamento. Uma economia (des) enraizada no pensamento de Polanyi, além de não estar sujeita às regulamentações externas, tem no lucro o principal motivo da produção, subordinando o motivo de subsistência. Assim, a economia apresenta autonomias, "a primeira pela inexistência de impedimentos e obstáculos exteriores, a segunda por the garantir certa primazia diante das outras esferas sociais" (Fleck, 2014).

Com efeito, segundo Polanyi (2000):

\footnotetext{
${ }^{3}$ Aliás, no que se refere ao conceito de "embeddedness" (imersão, enraizamento, incrustação) essa é uma das raras vezes que Polanyi menciona o respectivo conceito. Como salienta Machado (2010): "de fato, como é queixa comum em vários autores, o conceito de incrustação só é utilizado em "A grande transformação", em duas ocasiões. Todavia, o leitor munido da perspectiva adequada, ou seja, após a análise e estudo do pensamento polanyiano como um todo, conseguirá captar aí o sentido do conceito em toda a sua plenitude".
} 
A Cadeia Produtiva da Maçã em São Joaquim-SC sob as Perspectivas: Embeddedness e Formação de Preços e Quantidades

Frederico Santos Damasceno, Fabio Piccinini, Ấngelo Brião Zanela

Antes que o processo tivesse ido suficientemente longe, os trabalhadores já se amontoavam em novos locais de desolação, as assim chamadas cidades industriais da Inglaterra; a gente do campo se desumanizava em habitantes de favelas; a família estava no caminho da perdição e grandes áreas do país desapareciam rapidamente sob os montes da escória e refugos vomitados pelos "moinhos satânicos". Escritores de todas as opiniões e partidos, conservadores e liberais capitalistas e socialistas, referiam-se invariavelmente às condições sociais da Revolução Industrial como um verdadeiro abismo de degradação humana.

Fleck (2014) entende que a tese sustentada por Polanyi é a de que a formação social que surge neste período "rompe com os modelos precedentes em que o intercâmbio econômico ou comercial está inserido, subordinado às regulamentações que regem a vida social". O autor ainda destaca que: "a esfera da economia ganha assim uma autonomia diante das demais esferas, de modo que se torna um mecanismo autômato que fora designado por ele como "moinho satânico".

Polanyi (2000) argumentou que, de forma singular, a sociedade acredita na força de um mercado autorregulado. Nessa perspectiva, cria-se um cenário de utopias que, levado a cabo, acaba por desarranjar o tecido social. Tratando de tais práticas inerentes às economias de mercados autorregulados ${ }^{4}$, o respectivo autor acreditava no desmantelamento de redes socialmente estabelecidas, as quais são responsáveis pelas garantias de subsistência e bem-estar dos grupos que as compõem.

Por meio do pensamento de autores antropólogos, Polanyi (2000) relatou a existência de organizações sociais que dispensam a ação do mercado para a realização da troca entre produtos. Diante disso, "ele adota uma forma de abordagem institucionalista que busca descrever as sociedades analisadas por meio do exame da interação de suas instituições políticas, econômicas, sociais e culturais" (Fleck, 2014).

\footnotetext{
${ }^{4}$ A Grande Transformação de 1944 traz uma crítica aos economistas neoclássicos e de suas falácias economicistas, que consistem, sobretudo, em naturalizar o mercado, projetando as relações sociais mais modernas sobre o passado remoto (como faz, por exemplo, Adam Smith ao falar de uma propensão natural ao intercâmbio e à barganha; mas também toda a economia neoclássica ao adotar o modelo do homo economicus). (POLANYI, 2012); (FLECK, 2014).
} 
A Cadeia Produtiva da Maçã em São Joaquim-SC sob as Perspectivas: Embeddedness e Formação de Preços e Quantidades Frederico Santos Damasceno, Fabio Piccinini, Ấngelo Brião Zanela

Vale lembrar que Polanyi apresenta explicações das trocas em sociedades arcaicas e primitivas muito mais com o intuito de oferecer contrapontos que mostrem a singularidade da organização social que lhe era contemporânea do que propriamente com a finalidade de explicá-la.

Embora Polanyi (2000) enfatize o papel da sociedade na formação da economia, há no pensamento daqueles que compartilham do ideário de "sistema de negócios", por exemplo, a figura da empresa sendo a responsável por tal formação. Gertler (1997), menciona que se aceitarmos a ideia de Polanyi (2000) de que o mercado é socialmente construído e governado - e não uma forma "natural", dada, inevitável - então faz todo o sentido que as firmas em economias de mercado também devam ser "construídas" até certo ponto, pelo seu ambiente social institucional.

Esta convicção se afasta do conceito mais estrutural de Polanyi e inclina-se na direção de outra abordagem que teve grande influência na pesquisa sobre "embeddedness": a abordagem de Granovetter (1973) sobre a ação econômica e a estrutura social (1992).

Uma das principais preocupações de Granovetter seria a de evitar visões não socializadas da ação econômica, como na economia neoclássica, e visões excessivamente socializadas, oriundas da sociologia ${ }^{5}$. Granovetter, a exemplo de outros autores, rejeita o argumento de Polanyi, no que se refere à distinção entre economias de mercado enraizadas (antigas) e economias de mercado modernas e (des) enraizadas.

Segundo Williamson (2005); Vasconcellos (2006): "Granovetter defendendo a proposta de que o comportamento e as instituições econômicas são afetados por relações sociais, lança a proposição do enraizamento (embeddedness)". Nesse sentido, Vasconcellos (2006) ressalta que: "o comportamento econômico e as transações econômicas constituem o foco principal de interesse e o autor vai desenvolver seu

\footnotetext{
${ }^{5}$ Apesar da preocupação de Granovetter, Pike et.al. (2000, pg. 06), entende que: as result of imprecision and lack of conceptual clarity, the use of 'embeddedness' in economic geography has arguably been guilty of the same problem of the atomisation of economic actors and the denial of the ongoing influence of social relations identified in the original analysis of 'undersocialisation' in economics and 'over-socialisation' in sociology.
} 
A Cadeia Produtiva da Maçã em São Joaquim-SC sob as Perspectivas: Embeddedness e Formação de Preços e Quantidades

Frederico Santos Damasceno, Fabio Piccinini, Ẩngelo Brião Zanela

argumento contrapondo-o, a título de exemplo, aos pressupostos existentes na teoria dos custos de transação, de Williamson (1975; 1992; 1994; 1996; 2005)". Nesse contexto, a autora entende que são as relações sociais que de fato promoverão as transações econômicas e não as reduções de custos de transações.

Ao estabelecer uma sucinta distribuição das proposições estabelecidas por Granovetter sobre o "embeddedness", Vasconcellos (2006) contribuiu para a interpretação do respectivo conceito afirmando que:

i) tal conceito trouxe uma grande inovação para a análise das instituições e das transações econômicas, projetando luz sobre interfaces e interações entre as dimensões econômicas e relações sociais;

ii) mostrou que, dentro de um dado escopo de possibilidades técnicas e econômicas possíveis, prevalecerão aquelas determinadas pela natureza das relações sociais aí existentes;

iii) salientou que não existe "relação mercantil" pura. Relações mercantis encontram-se enraizadas em relações sociais e é impossível avaliá-las de maneira segmentada ou independente.

Revendo os trabalhos de Polanyi e Granovetter e entendendo as origens do conceito de "embeddedness", percebe-se facilmente que o "enraizamento" tem papel importante perante as atividades econômicas, seja em sociedades primitivas, seja nas economias de mercado modernas. Assim, não é apenas o mecanismo de preços que molda a natureza da troca econômica, mas a interação social de atores individuais e coletivos (Wilkinson, 1997).

A literatura consagrada tratou de explicar como os dois autores inovaram a análise das instituições e das transações econômicas. Este subitem, por sua vez, destacou algumas das principais contribuições de cada autor sob o conceito de "embeddedness". O próximo passo será o de dimensionar a importância desse conceito em relação ao desenvolvimento regional e territorial. 
A Cadeia Produtiva da Maçã em São Joaquim-SC sob as Perspectivas: Embeddedness e

Formação de Preços e Quantidades

Frederico Santos Damasceno, Fabio Piccinini, Ẩngelo Brião Zanela

\subsection{Embeddedness e sua amplitude}

O próprio Granovetter ao reformular o conceito de "embeddedness", concluiu que seria possível abrir espaço para que o respectivo conceito fosse amplamente utilizado nas mais variadas formas e contextos. Onias (1997) mencionou que:

The idea of embeddedness is an attempt to better understand those aspects in firms' external relations that cannot be captured by traditional concepts. They tend to be the "soft" items that escape direct measurement. They are difficult to grasp even in qualitative analysis because they are often "taken for granted" by actors and, thus, tend to feature only indirectly in actors' own account. Nevertheless, they may affect the competitiveness of firms and the development of regions. In particular, it might be helpful in capturing those aspects of economic life that are not 'purely economic', and that are not considered by traditional theories and conceptualisations.

Ao buscar compreender a proposta conceitual de Granovetter, vários autores buscaram reformulações ou aplicações, usando "embeddedness" em diversos estudos, incluindo, como já mencionado, aqueles atrelados à geografia econômica ${ }^{6}$.

É importante ressaltar que o conceito de "embeddedness" na atividade econômica propõe que as organizações formais, empresas, desenvolvam ações "num determinado contexto social, institucional e espacial" (Vale, 2000). Assim, as dimensões territorial e espacial são importantíssimas para compreender o avanço da atividade econômica. Martin (1994); Hess (2004), por exemplo, entendem que, além de ser uma questão de relações sociais, a ação econômica e, portanto, a imersão é inerentemente espacial.

Schneider (2009) entende que o território se tornou uma variável crucial para explicar as dinâmicas econômicas relativas a diferentes espaços. As condições históricas e culturais e as características socioeconômicas das diversas regiões jogam

\footnotetext{
${ }^{6}$ A geografia econômica é o estudo da localização, distribuição e organização espacial das atividades econômicas na Terra, e está focada na: localização de indústrias e atividades comerciais no atacado e varejo; em rotas comerciais e de transporte; e nas mudanças de valor do mercado imobiliário. Podem abranger análises atreladas a transporte, agricultura, localização industrial, comércio internacional, e a organização espacial e funções das atividades de negociação.
} 
A Cadeia Produtiva da Maçã em São Joaquim-SC sob as Perspectivas: Embeddedness e Formação de Preços e Quantidades

Frederico Santos Damasceno, Fabio Piccinini, Ẩngelo Brião Zanela

um papel importante. Sua diversidade explica em grande parte as diferenças de trajetórias de desenvolvimento ordenadas segundo circunstâncias históricas e geográficas.

Segundo Schneider (2009):

O espaço deixa de ser um simples suporte para se tornar território, que é o ponto de reencontro dos atores do desenvolvimento, o lugar onde se organizam formas de cooperação entre empresas, onde se gerencia a divisão social do trabalho, enfim, o lugar de reencontro entre as formas de mercado e as formas de regulação social. O território torna-se um componente permanente do desenvolvimento.

As relações sociais são formadas a partir de instituições formais e informais ${ }^{7}$ numa estrutura espacial ativa que é, simultaneamente, causa e consequência do processo de enraizamento da ação econômica.

Vale (2000) acredita também que: "no âmbito das instituições formais, as relações interfirmas decorrem num determinado quadro social territorializado, capaz de potenciar - mas também de inibir - a eficiência do tecido produtivo. Assim, a identidade territorial está na base - e também é consequência - da imbricação da ação econômica".

Para Vasconcellos (2006), o território é tanto um lócus para o exercício da cooperação como também para a competição, o acirramento das disputas individuais e o surgimento de facções. A autora (2006) ainda ressalta que as dimensões supracitadas e suas relações com a atividade econômica podem ser observadas da seguinte forma ${ }^{8}$ :

7a) Por instituições formais entende-se: organizações, sistemas político-administrativos, etc.; b) Por instituições informais entende-se: tradições, costumes, cultura, emoções, etc. (Vale, 2000).

${ }^{8}$ Ainda que se leve em consideração a contraposição por Granovetter aos pressupostos existentes na teoria dos custos de transação, de Williamson (1975; 1992; 1994; 1996). 
A Cadeia Produtiva da Maçã em São Joaquim-SC sob as Perspectivas: Embeddedness e Formação de Preços e Quantidades

Frederico Santos Damasceno, Fabio Piccinini, Ấngelo Brião Zanela

$\mathrm{Na}$ dimensão espacial, tal conceito tem sido utilizado para explicar a evolução e o sucesso econômico alcançado por certas regiões e aglomerações produtivas, baseadas em especificidades de sistemas econômicos, sociais e políticos presentes no local e, eventualmente, em sintonia com outras abordagens, tais como a teoria dos custos de transação ou economias de aglomeração ou, então, associado a algumas concepções derivadas da literatura sobre capital social (Vasconcellos, 2006).

Para Grabher (1993) a imbricação caracteriza-se por (re) fluxos entre capital e trabalho, estado e instituições ou mesmo entre divisões étnicas e de gênero que, se inscrevem num quadro territorial bem delimitado. Em termos práticos, a investigação realizada em geografia econômica segundo esta perspectiva reporta-se ao estudo da forma e do modo de ancoragem da empresa ou de uma indústria (subject) à região (object).

No âmbito da geografia econômica a relação entre a dimensão territorial e a espacial e o conceito de "embeddedness" é discutida desde os anos de 1990. Um trabalho importante, nesse sentido, é o de Dicken e Thrift (1992). Nele, os autores (1992), elucidam que: "as organizações empresariais são produzidas por meio de um processo histórico de incorporação que envolve uma interação entre as características cognitivas, culturais, sociais, políticas e econômicas específicas do "território de origem" de uma empresa, operações geograficamente dispersas e as pressões competitivas e tecnológicas que a afetam".

A amplitude descrita nas proposições de Dicken e Thrift (1992) acabou levando tanto Oinas (1997), quanto Vale (2006), a acreditarem que em relação ao trabalho de Dickens \& Thrift (1992), a concepção espacial de embeddedness mantém o mesmo caráter vago da concepção original de Granovetter. No entanto, Vale (2006) não deixou de levar em consideração a observação atenta de Oinas (1997), ou seja: que, embora a ambiguidade esteja evidente no uso contemporâneo do termo, e a noção de embeddedness permaneça vaga, ela direciona nossa atenção para aspectos de 
A Cadeia Produtiva da Maçã em São Joaquim-SC sob as Perspectivas: Embeddedness e Formação de Preços e Quantidades

Frederico Santos Damasceno, Fabio Piccinini, Ấngelo Brião Zanela

relações de firmas e seu ambiente que não são muito bem compreendidos ou conceituados por meio de dados.

A abordagem espacial traz à tona a importância das relações baseadas em confiança. Nesse contexto a grande maioria da literatura sobre embeddedness enfatiza o papel central de relações pessoais concretas e redes de relações para gerar tal confiança. Os proponentes da literatura de embeddedness local concluíram que a proximidade espacial facilita as relações baseadas na confiança, uma vez que "a construção de confiança é geralmente difícil de alcançar a longas distâncias devido à necessidade de interação face a face." (Staber, 1996).

Pode-se assim dizer que "a região é agora contribuinte para a dinâmica do capitalismo moderno, não apenas um resultado" (Storper, 1997). Sobre o pensamento de Storper (1997) e Schneider (2009) menciona que tal ideia vem desconstruir as metanarrativas dos modelos de desenvolvimento fordistas e pós-fordistas e destaca a natureza pluralista, heterogênea e híbrida dos processos de mudança social e econômica. Para o autor (2009), "um dos elementos chaves desta literatura é a ideia de que os processos de desenvolvimento que apresentam os melhores indicadores de desempenho são aqueles assentados em dinâmicas territoriais". Por fim, o autor (2009) enfatiza:

Do ponto de vista material e produtivo os territórios tornam-se sistemas produtivos locais que territorializam o lugar em que transcorre uma pluralidade de formas de justificação da ação humana (reciprocidade, cooperação, concorrência, disputa). Neste sentido, os territórios não possuem apenas uma dimensão econômica e material, mas também cultural e cognitiva. Neste sentido, é um resultado, pois "constituem-se em espaços particulares que permitem operar uma mediação entre o indivíduo e o exterior.

Diante do que já foi discutido, será complementar a análise de mais dois conceitos importantes: (a) redes sociais; e (b) arranjos empresariais. Em relação ao primeiro conceito, Gonçalo e Reyes Junior (2012) entendem como: "um conjunto de dois elementos: atores (pessoas, instituições ou grupos) e suas conexões". Para 
A Cadeia Produtiva da Maçã em São Joaquim-SC sob as Perspectivas: Embeddedness e Formação de Preços e Quantidades Frederico Santos Damasceno, Fabio Piccinini, Ẩngelo Brião Zanela

Emirbayer; Goodwin (1994); Wasserman e Faust (1994); Gonçalo e Reyes Junior (2012), as redes sociais são contatos que possibilitam o relacionamento entre vários e diferentes atores, cujos conteúdos e propriedades estruturais podem ser diversificados. Tal conceito é justificado ao se admitir que as redes sociais sejam um conjunto de pessoas, ou organizações, ou ainda, outras entidades sociais conectadas por relacionamentos sociais, motivados pela amizade e por relações de trabalho ou compartilhamento de informações e, por meio dessas ligações, vão construindo e reconstruindo a estrutura social.

Revendo a proposta estabelecida por Granovetter (1973), percebe-se que foram apresentados os conceitos de ligações fortes e ligações fracas. Segundo ele, os atores (pessoas) que têm relacionamentos mais distantes (ligações fracas), estão envolvidos em menor grau, enquanto que, com ligações fortes, definidas pelos atores (pessoas) mais próximos, há um maior envolvimento. Na visão de Gonçalo e Reyes Junior (2012), Granovetter salientou que: "as ligações fracas são responsáveis pela baixa densidade em uma rede, ou seja, em que muitas das possibilidades de relacionamento estão ausentes, enquanto que conjuntos consistentes dos mesmos indivíduos e seus parceiros mais próximos estão densamente ligados". Os respectivos autores (2012) ressaltam que Granovetter (1973), ainda mencionaria que "os limites das redes são provocados pelas relações fracas, o que por sua vez permite conectar grupos até então sem conexões intrínsecas. A existência de laços fracos ainda seria primordial para que esses indivíduos atinjam mais pessoas sem que haja perda de confiança".

Os laços fracos geralmente se fazem presentes na veiculação de informações e na construção de coordenação política. Para Carrol e Fennema (2002), os laços fortes mostram-se muito importantes diante de fenômenos de coesão, comando e relações mais verticalizadas. No entanto, não são excludentes, podendo ser considerados inclusive na análise de uma mesma situação. As redes costumam, como qualquer estrutura, ser duradouras pois, embora estejam em contínua transformação, pela construção ou rompimento de vínculos, a parcela em transformação tende a ser 
A Cadeia Produtiva da Maçã em São Joaquim-SC sob as Perspectivas: Embeddedness e Formação de Preços e Quantidades

Frederico Santos Damasceno, Fabio Piccinini, Ẩngelo Brião Zanela

relativamente pequena comparada ao conjunto dos vínculos (Gonçalo e Reyes Junior, 2012).

\section{ASPECTOS METODOLÓGICOS}

Enquanto a revisão teórica trata de apresentar o conceito de embeddedness, sua amplitude $\mathrm{e}$ as possibilidades dos vínculos socioculturais estabelecidos serem definitivos à consolidação da cadeia produtiva de maçã no município de São Joaquim, a variação dos preços será investigada diante do comportamento da série de tempo que revelará a presença de componentes de tendência e de sazonalidade.

São realizadas previsões utilizando os métodos de Holt-Winters aditivo e multiplicativo, baseados em três equações alisadoras: de nível, tendência e sazonalidade.

A fonte de dados baseia-se nas pesquisas elaboradas pela Companhia Nacional de Abastecimento (CONAB), contendo as quantidades e os preços da maçã no respectivo mercado entre os anos de 2009-2019.

Para a realização das previsões, é utilizado o pacote estatístico Eviews 9, retirando os dados dos últimos 12 meses que compreendem o período de julho de 2018 até junho de 2019, provendo, assim, as previsões dos modelos.

São determinados os parâmetros para as previsões dos modelos aditivo e multiplicativo, sendo: alfa $(\alpha)$, beta $(\beta)$ e gama $(\gamma)$ e as medidas de acurácia SSR e RMSE. Em seguida são comparados os resultados, entendendo-se que há poucas diferenças entre os modelos Holf-Winter aditivo e Holf-Winter multiplicativo. 
A Cadeia Produtiva da Maçã em São Joaquim-SC sob as Perspectivas: Embeddedness e Formação de Preços e Quantidades

Frederico Santos Damasceno, Fabio Piccinini, Ẩngelo Brião Zanela

\section{APRESENTAÇÃO DOS RESULTADOS}

\subsection{Embeddedness: o processo histórico, vínculos socioculturais e organização produtiva em São Joaquim - SC}

Em São Joaquim-SC um conjunto de empresas concentra-se geográfica e setorialmente. A integração vertical estabelecida não impediu que a produção de maçãs também pudesse ser realizada por um grande número de pequenos produtores, o que por sua vez, define as características fundamentais dos chamados: "arranjos empresarias".

Estas organizações foram estabelecidas regionalmente por meio de processos históricos, incorporados mediante características cognitivas, culturais, sociais, políticas e econômicas. Exemplos desse processo mostram-se evidentes quando da ocorrência do transporte de gado para o interior de São Paulo e Minas Gerais na década de 1750, marcando o início da ocupação territorial por fazendeiros gaúchos e da pecuária passando a ser a principal atividade econômica em âmbito regional. Já em 1956, a "Primeira Festa Municipal da Maçã" em São Joaquim se transformou em um movimento cultural que popularizou a cultura da macieira, impactando sobre o quantum de vendas de maçã pelo país.

A disseminação da cultura da maçã, favorecida pela crise na pecuária e pela diminuição das reservas de araucárias nos anos 1960, contou com a ação do poder público a partir do empenho por parte de seus gestores para o enfrentamento do desemprego e a consequente falta de renda. Deu-se, assim, início às mudanças nas políticas agrícolas em busca de outras fontes de recursos econômicos, entre elas a fruticultura ${ }^{9}$. Como instrumentos de mudança, foi aprovada a lei " $n^{\circ} 5.106 / 66$ " (Lei dos Incentivos Fiscais), importante ao desenvolvimento do cultivo de maçã, o que, por sua vez, permitiu o abatimento de $50 \%$ do imposto de renda para aplicação de reflorestamento a partir de árvores frutíferas (Petri, Leite, Couto, \& Francescatto, 2011); (Brighenti, Vieira, Pasa, \& Ciotta, 2016).

\footnotetext{
${ }^{9}$ Além de permitir que a implantação de macieiras fosse disseminada pelos Estados do Sul do Brasil.
} 
A Cadeia Produtiva da Maçã em São Joaquim-SC sob as Perspectivas: Embeddedness e Formação de Preços e Quantidades Frederico Santos Damasceno, Fabio Piccinini, Ẩngelo Brião Zanela

Os anos 2000 revelam um período de modernização e melhorias em termos de estrutura produtiva (armazenamento, classificação e embalagens). As melhorias, também, ocorrem nos pomares com o avanço nas técnicas de cultivo, a exemplo das coberturas de pomares, destinadas à proteção contra o granizo (Marquis, 2006). Com efeito, segundo EPAGRI (2017), as safras desse ano registraram números expressivos: "foram relacionados 2.749 produtores de maçã regionalmente distribuídos, sendo que 2.199 fruticultores localizam-se em São Joaquim". O volume de maçãs produzido na região foi de aproximadamente 400 mil toneladas e a pomicultura foi responsável por aproximadamente 70\% do PIB do município de São Joaquim (Brighenti et al. 2016).

Características peculiares à região, a forma de produção e a composição do produto devem ser salientados. Na região de São Joaquim, há o predomínio de pequenos agricultores que produzem maçã em propriedades diversificadas, utilizando mão de obra familiar, embora a produção empresarial seja responsável pelo maior volume. A respectiva região tem considerável disponibilidade de terras para novos cultivos e um clima frio, com maior diferença de temperatura entre o dia e a noite. Estas características favorecem a cultura da maçã, proporcionando maior concentração de açúcares e frutas de coloração mais intensa.

A região tornou-se contribuinte à dinâmica de mercado, em que os processos de desenvolvimento apresentam indicadores de desempenho assentados na dinâmica territorial. É importante que se reforce a importância de "embeddedness" diante dos contextos social e econômico estabelecidos. Ou seja, torna-se evidente que a cadeia produtiva de maçã em São Joaquim-SC está submersa no papel realizado pelas instituições, nos valores, nas características e sabores, intrínsecos ao produto regionalmente ofertado. Os aspectos institucionais passaram a ser compreendidos e permitiram a valorização das características sociais desse mercado.

Não menos importante às ações precursoras de "embeddedness" para a evolução da produção de maçã em São Joaquim é o papel atribuído às redes sociais estabelecidas. O ano de 1968 foi marcado pela participação da ação pública em um projeto que promoveria o cultivo de maçãs: o "Projeto de Fruticultura de Clima 
A Cadeia Produtiva da Maçã em São Joaquim-SC sob as Perspectivas: Embeddedness e Formação de Preços e Quantidades Frederico Santos Damasceno, Fabio Piccinini, Ấngelo Brião Zanela

Temperado" (PROFIT), criado pela Lei no 4.263 (Petri et al., 2011), adotado em São Joaquim e amparado tecnicamente pela então criada "Associação de Crédito e Assistência Rural do Estado de Santa Catarina" (ACARESC). Nesse período firmou-se um acordo para amparo técnico à cultura de maçã em São Joaquim com o governo japonês, por meio da Agência de Cooperação Internacional (JICA).

O cultivo da maçã começou a se modernizar, em particular, pela introdução de mudas importadas as quais resultaram no aumento da produtividade dos pomares. Aqui se percebe claramente, de que forma as redes sociais se estabeleceram por meio de um conjunto de pessoas, organizações, entidades conectadas por relacionamentos pessoais e motivados pela amizade, por relações de trabalho ou compartilhamento de informações e que acabou por construir uma estrutura social.

A imbricação também é caracterizada por (re) fluxos entre capital e trabalho, inseridos em um espaço territorial bem delimitado. Com isso, a primeira festa nacional da maçã em 1978 coincidiu com a implantação da fruticultura mediante uma produção racionalizada e mecanizada, o que possibilitou efeitos multiplicadores nos investimentos de vários setores e atraiu mão de obra qualificada e recursos para a realização de novos projetos.

Com o intuito de minimizar os efeitos de operações geograficamente dispersas, de pressões competitivas e tecnológicas, as quais afetam todo processo produtivo, foram criadas entre os anos 1980 e 2000, as cooperativas (arranjos empresariais) importantes para o desenvolvimento do setor e da região. É o caso da Cooperativa Agrícola de São Joaquim (Sanjo) e da Cooperativa Agrícola Frutas de Ouro. Ambas, iniciaram suas atividades com um grupo de fundadores de 34 fruticultores. Ao se reverem as palavras de Vasconcellos (2006), pode-se dizer que o respectivo território passou a ser tanto um lócus para o exercício da cooperação como também para a competição.

Na próxima seção faremos a análise pela relação do mercado, onde se procurou analisar o comportamento dos preços e das quantidades através de uma série de tempo para o município de São Joaquim, bem como para o estado de Santa Catarina. 
A Cadeia Produtiva da Maçã em São Joaquim-SC sob as Perspectivas: Embeddedness e Formação de Preços e Quantidades Frederico Santos Damasceno, Fabio Piccinini, Ẩngelo Brião Zanela

\subsection{Cadeia produtiva da maçã em São Joaquim-SC sob a perspectiva de variações de preços e quantidades}

No Brasil, os cultivares plantados são: Anna, Brasil, Condessa, Catarina, Delicious, Eva, Golden, Granny Smith, Gala e Fuji. O cultivo da Fuji, por sua vez, concentra-se na região de São Joaquim, oriunda das técnicas de plantio, do perfil empreendedorismo atrelado a aprendizado repassado pelos primeiros produtores às novas gerações e pelo apoio institucional, público e privado, que levaram a uma produtividade média que "varia de 15 a 30 toneladas por hectare de frutos em pomares" (EPAGRI, 2017).

A produção da maçã constitui-se uma importante atividade agrícola no estado de Santa Catarina, que é o maior produtor do país. De acordo com o Censo Agro do IBGE, na última safra em 2019, foram colhidas 593.447.372 toneladas dessa fruta no estado. E merece destacar que a Empresa de Pesquisa Agropecuária e Extensão Rural de Santa Catarina (EPAGRI) estima que São Joaquim e região devem colher aproximadamente 370 mil toneladas.

O manejo da cultura da maçã para a execução da poda (seca e verde), do raleio dos frutos e da colheita, requer um número expressivo de trabalhadores na contratação de mão de obra temporária. Ressalta-se assim, da Tabela - 1 abaixo que: 
A Cadeia Produtiva da Maçã em São Joaquim-SC sob as Perspectivas: Embeddedness e Formação de Preços e Quantidades Frederico Santos Damasceno, Fabio Piccinini, Ấngelo Brião Zanela

Tabela 1

Número de admitidos no município de São Joaquim/SC

\begin{tabular}{lccc}
\hline Período & $\begin{array}{c}\text { Trabalhador no cultivo de árvores } \\
\text { frutíferas }\end{array}$ & Total trabalhador & Participação no total (\%) \\
\hline 2009 & 3484 & 5917 & $58,88 \%$ \\
2010 & 3229 & 5752 & $56,14 \%$ \\
2011 & 3056 & 5489 & $55,67 \%$ \\
2012 & 2241 & 5427 & $41,29 \%$ \\
2013 & 2065 & 4863 & $42,46 \%$ \\
2014 & 2055 & 5425 & $37,88 \%$ \\
2015 & 1881 & 4893 & $38,44 \%$ \\
2016 & 1738 & 4326 & $40,18 \%$ \\
2017 & 1652 & 5337 & $30,95 \%$ \\
2018 & 1874 & 4713 & $39,76 \%$ \\
${ }^{*} 2019$ & 1275 & 3093 & $41,22 \%$ \\
\hline
\end{tabular}

Nota. Fonte: Caged

* Informações dos admitidos de janeiro a junho de 2019.

A tabela 1 apresenta a participação de mão de obra dos admitidos no total de emprego gerado no município de São Joaquim/SC para a atividade de cultivo. As categorias de trabalhadores no cultivo de arvores frutíferas no município compreendem em sua maior parte trabalhadores no cultivo de maçã, se comparado, por exemplo, ao cultivo da uva no mesmo município. É uma produção que, inclusive, participa do mercado externo, como mostra a Tabela 2 a seguir: 
A Cadeia Produtiva da Maçã em São Joaquim-SC sob as Perspectivas: Embeddedness e Formação de Preços e Quantidades Frederico Santos Damasceno, Fabio Piccinini, Ẩngelo Brião Zanela

Tabela 2

Exportação de maçã do município de São Joaquim/SC

\begin{tabular}{lcccccc}
\hline Período & Kg líquido & US\$ FOB & $\begin{array}{c}\text { Total kg } \\
\text { líquido }\end{array}$ & $\begin{array}{c}\text { Total US\$ } \\
\text { FOB }\end{array}$ & $\begin{array}{c}\text { Participação } \\
\text { no total Kg } \\
\text { liquido }\end{array}$ & $\begin{array}{c}\text { Participação } \\
\text { em US\$ } \\
\text { FOB }\end{array}$ \\
\hline $2015^{10}$ & 21168 & 16797 & 922231 & 551966 & $2,30 \%$ & $3,04 \%$ \\
2016 & 4023048 & 2208497 & 5487634 & 2953128 & $73,31 \%$ & $74,79 \%$ \\
2017 & 9814421 & 6735683 & 11086421 & 7401648 & $88,53 \%$ & $91,00 \%$ \\
2018 & 7149233 & 4762524 & 8108033 & 5239882 & $88,17 \%$ & $90,89 \%$ \\
${ }^{*} 2019$ & 5041831 & 3621287 & 5773427 & 3987304 & $87,33 \%$ & $90,82 \%$ \\
\hline
\end{tabular}

Nota. Fonte: Microdados do MDIC

* Informações das exportações de janeiro a junho de 2019.

\subsection{Modelo}

Para analisar a relação do preço e da quantidade ao longo do tempo são utilizados modelos de séries de tempo formados por uma função de uma variável independente tempo $(\mathrm{t})$, relacionada a um processo em que há uma descrição matemática de forma desconhecida. Há de se destacar que o comportamento de uma série de tempo pode, em determinados momentos, ser antecipado mediante procedimentos estocásticos, visto que estas séries possuem como atributo a não previsibilidade como uma função determinística.

As análises em relação a esses comportamentos da série de tempo revelam a presença de componentes de tendência e de sazonalidade. Por isso, torna-se necessária para efetuar previsões a utilização dos métodos de Holt-Winters aditivo e multiplicativo. Esses se baseiam em três equações alisadoras, sendo a primeira para o nível, a segunda para a tendência e a terceira para a sazonalidade. Assim, conforme as apresentações no Quadro - 1:

\footnotetext{
${ }^{10} \mathrm{Em} 2015$ a participação da maçã em São Joaquim/SC na pauta de exportação não é expressiva devido à exportação de madeira. Código do SH4: 4407 - Madeira serrada ou endireitada longitudinalmente, cortada ou desenrolada, mesmo aplainada, polida ou unida pelas extremidades, de espessura superior a $6 \mathrm{~mm}$.
} 
A Cadeia Produtiva da Maçã em São Joaquim-SC sob as Perspectivas: Embeddedness e Formação de Preços e Quantidades Frederico Santos Damasceno, Fabio Piccinini, Ấngelo Brião Zanela

\begin{tabular}{|c|l|l|}
\hline & Holt-Winters Multiplicativo & Holt-Winters Aditivo \\
\hline Nível & $L_{t}=\alpha \frac{Y_{t}}{S_{t-s}}+(1-\alpha)\left(L_{t-1}+b_{t-1}\right)$ & $L_{t}=\alpha\left(Y_{t}-S_{t-s}\right)+(1-\alpha)\left(L_{t-1}+b_{t-1}\right)$ \\
\hline Tendência & $b_{t}=\beta\left(L_{t}-L_{t-1}\right)+(1-\beta) b_{t-1}$ & $b_{t}=\beta\left(L_{t}-L_{t-1}\right)+(1-\beta) b_{t-1}$ \\
\hline Sazonalidade & $S_{t}=\gamma \frac{Y_{t}}{S_{t}}+(1-\gamma) S_{t-s}$ & $S_{t}=\gamma\left(Y_{t}-L_{t}\right)+(1-\gamma) S_{t-s}$ \\
\hline
\end{tabular}

Quadro 1. Equações comparativas dos modelos de Holt-Winters multiplicativo e aditivo Fonte: Lúcio et. al. (2010).

Sendo:

S - comprimento da sazonalidade; $L_{t}$ - nível da série;

$\beta_{t}$ - tendência; $S_{t}$ - componente sazonal;

$Y_{t}$ - valor observado;

$\alpha, \beta, \gamma$ - parâmetros exponenciais alisadores do nível, da tendência e da sazonalidade.

A partir das equações anteriores obtêm-se as equações de previsão:

$F_{t+m}=\left(L_{t}+b_{t} m\right) S_{t-s+m}$ equação da previsão de Holt-Winters Multiplicativo

$F_{t+m}=L_{t}+b_{t} m+S_{t-s+m}$ equação da previsão de Holt-Winters Aditivo 
A Cadeia Produtiva da Maçã em São Joaquim-SC sob as Perspectivas: Embeddedness e Formação de Preços e Quantidades Frederico Santos Damasceno, Fabio Piccinini, Ấngelo Brião Zanela

\subsection{Discussão dos resultados}

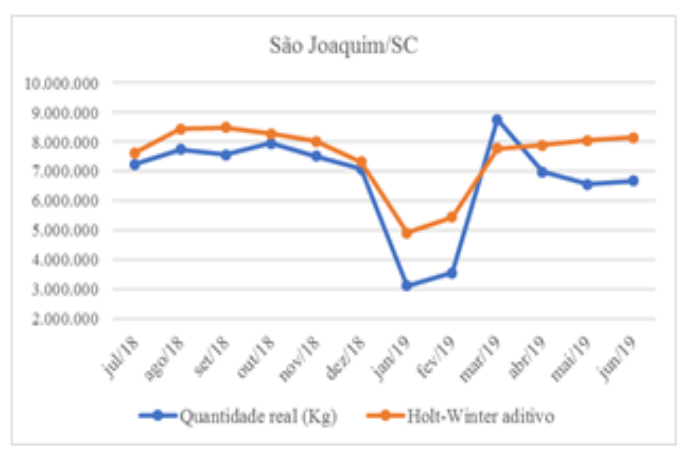

(1)

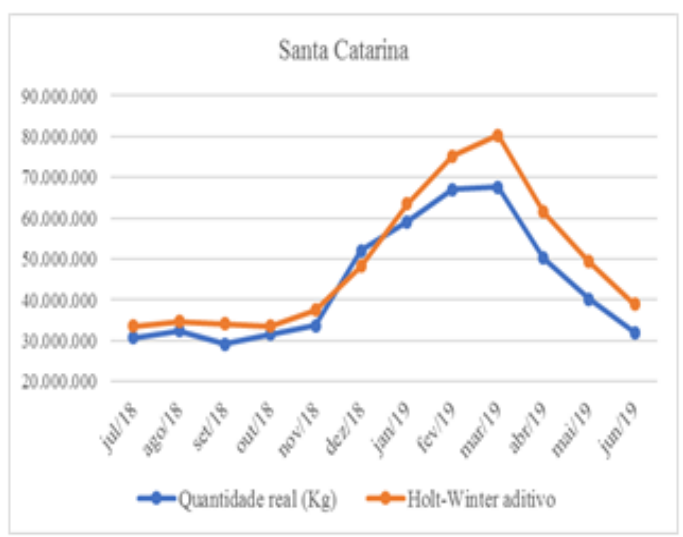

(3)

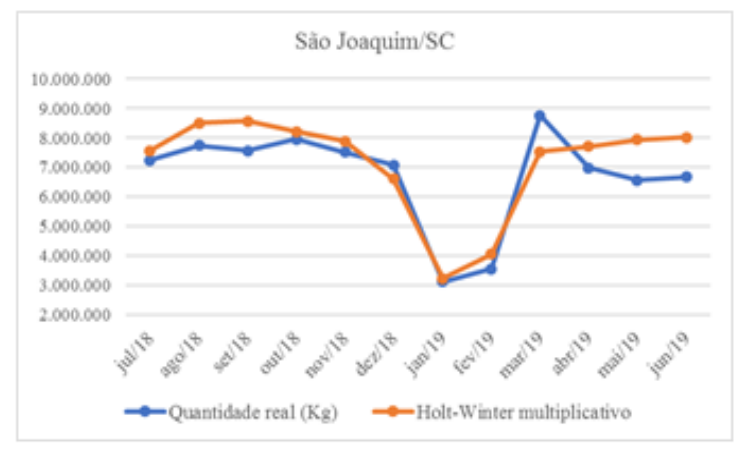

(2)

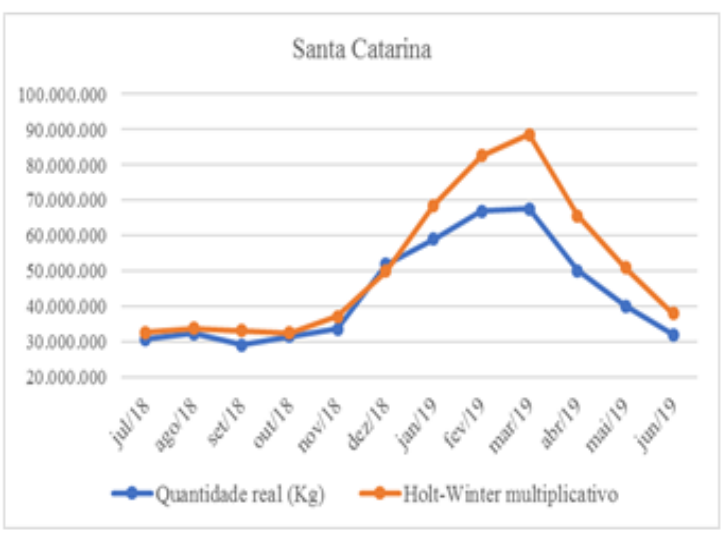

(4) 
A Cadeia Produtiva da Maçã em São Joaquim-SC sob as Perspectivas: Embeddedness e Formação de Preços e Quantidades Frederico Santos Damasceno, Fabio Piccinini, Ấngelo Brião Zanela

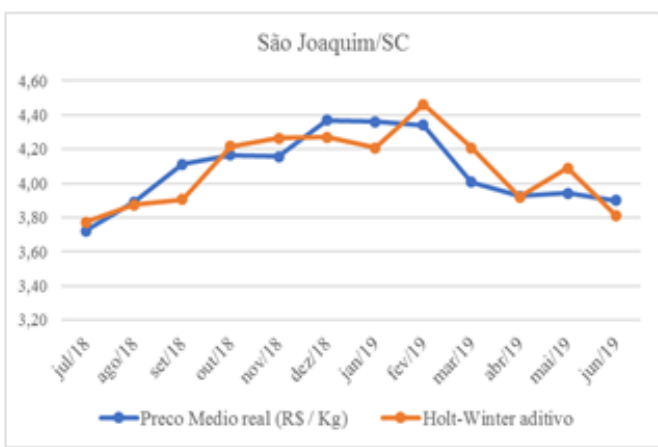

(5)

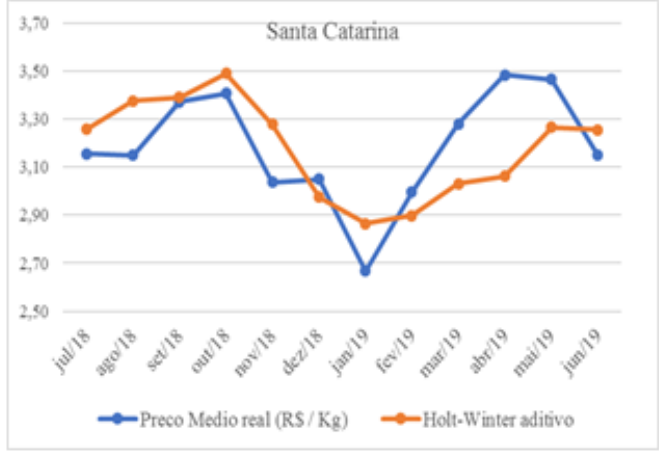

$(7)$

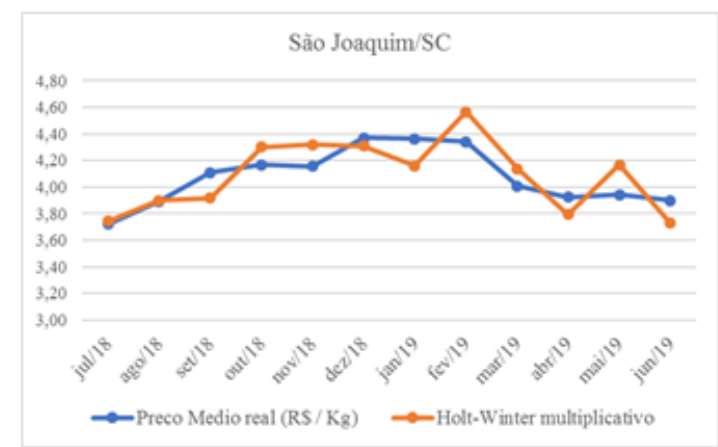

(6)

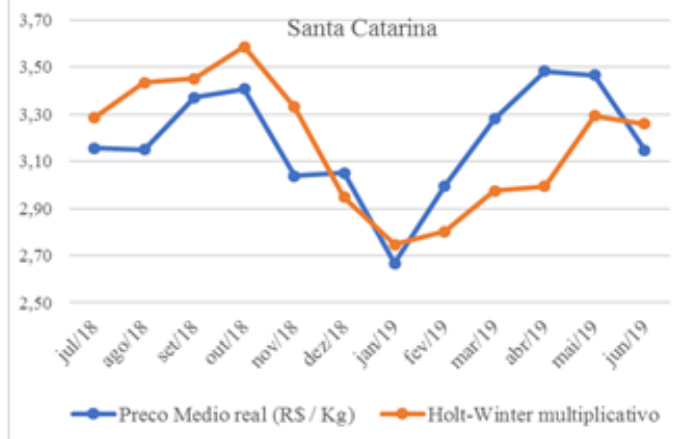

(8)

Gráficos (1 a 8). Utilização dos métodos de Holt-Winters aditivo e multiplicativo para previsão da quantidade negociada de maçã do município de São Joaquim-SC

Fonte: Elaboração própria com base nos dados da CONAB

Como parte da estratégia metodológica, a realização das previsões foi feita utilizando-se o pacote estatístico Eviews 9, retirando-se os dados dos últimos 12 meses que compreendem o período de julho de 2018 até junho de 2019 para avaliar a previsão dos modelos. Foram determinados os parâmetros para as previsões dos modelos aditivo e multiplicativo, sendo: alfa $(\alpha)$, beta $(\beta)$ e gama $(\gamma)$ e as medidas de acurácia SSR e RMSE conforme apresentação nos Gráficos - (1 a 8) acima e no Quadro - (2) a seguir.

Comparando os resultados, existem poucas diferenças entre os modelos HoltWinter e o modelo Holt-Winter multiplicativo. E, já que os resultados dos modelos aditivo e multiplicativo são parecidos, foram utilizados os dois para realizar a previsão dos dados para o ano de 2020. A quantidade e preço da maçã prevista para São 
A Cadeia Produtiva da Maçã em São Joaquim-SC sob as Perspectivas: Embeddedness e Formação de Preços e Quantidades Frederico Santos Damasceno, Fabio Piccinini, Ẩngelo Brião Zanela

Joaquim/SC e o estado de Santa Catarina, que serão negociados na Ceasa de Curitiba, encontram-se nas Tabelas (3) e (4).

\begin{tabular}{|c|c|c|c|c|c|c|c|c|}
\hline \multirow[b]{2}{*}{$\begin{array}{c}\text { Parâmetro } \\
\text { s/Medidas } \\
\text { de } \\
\text { acurácia }\end{array}$} & \multicolumn{4}{|c|}{ Holt-Winter aditivo } & \multicolumn{4}{|c|}{ Holt-Winter multiplicativo } \\
\hline & $\begin{array}{l}\text { Quantidad } \\
\text { e São } \\
\text { Joaquim }\end{array}$ & $\begin{array}{c}\text { Quantida } \\
\text { de SC }\end{array}$ & $\begin{array}{l}\text { Preço } \\
\text { São } \\
\text { Joaquim }\end{array}$ & $\begin{array}{l}\text { Preço } \\
\text { SC }\end{array}$ & $\begin{array}{l}\text { Quantidad } \\
\text { e São } \\
\text { Joaquim }\end{array}$ & $\begin{array}{c}\text { Quantidad } \\
\text { e SC }\end{array}$ & $\begin{array}{c}\text { Preço } \\
\text { São } \\
\text { Joaqui } \\
\text { m }\end{array}$ & $\begin{array}{l}\text { Preço } \\
\text { SC }\end{array}$ \\
\hline Alpha $(\alpha)$ & 0,49 & 0,57 & 0,60 & 0,89 & 0,66 & 0,69 & 0,59 & 0,81 \\
\hline Beta $(\beta)$ & 0,00 & 0,00 & 0,00 & 0,00 & 0,00 & 0,00 & 0,00 & 0,00 \\
\hline $\begin{array}{c}\text { Gamma } \\
\text { (v) }\end{array}$ & 0,00 & 0,00 & 0,00 & 0,00 & 0,00 & 0,00 & 0,00 & 0,00 \\
\hline SSR & $8,30 \mathrm{E}+13$ & $\begin{array}{c}2,06 E+1 \\
5\end{array}$ & 16,02 & 5,22 & $8,99 \mathrm{E}+13$ & $2,24 \mathrm{E}+15$ & 16,90 & 4,94 \\
\hline RMSE & $853.207,88$ & $\begin{array}{c}4.248 .52 \\
6,04\end{array}$ & 0,36 & 0,21 & $887.894,18$ & $\begin{array}{c}4.431 .748 \\
61\end{array}$ & 0,37 & 0,21 \\
\hline
\end{tabular}

Quadro 2. Resultado dos parâmetros e medidas de acurácia para os modelos aditivo e multiplicativo das quantidades e preços.

Fonte: Elaboração própria com base nos dados da CONAB. 
A Cadeia Produtiva da Maçã em São Joaquim-SC sob as Perspectivas: Embeddedness e Formação de Preços e Quantidades Frederico Santos Damasceno, Fabio Piccinini, Ẩngelo Brião Zanela

Tabela 3

Quantidade e preço previsto de maçã de São Joaquim/SC negociada na Ceasa de Curitiba

\begin{tabular}{lcccc}
\hline Período & $\begin{array}{c}\text { Quantidade (kg) } \\
\text { Holt-Winter } \\
\text { Aditivo }\end{array}$ & $\begin{array}{c}\text { Holt-Winter } \\
\text { Multiplicativo }\end{array}$ & $\begin{array}{c}\text { Preço (kg) } \\
\text { Holt-Winter } \\
\text { Aditivo }\end{array}$ & $\begin{array}{c}\text { Holt-Winter } \\
\text { Multiplicativo }\end{array}$ \\
\hline julho/2019 & $6.945 .297,40$ & $6.957 .310,44$ & 3,87 & 3,84 \\
agosto/2019 & $7.727 .597,60$ & $7.792 .132,22$ & 4,01 & 4,02 \\
setembro/2019 & $7.744 .688,70$ & $7.830 .596,49$ & 4,03 & 4,04 \\
outubro/2019 & $7.604 .301,50$ & $7.580 .788,96$ & 4,22 & 4,31 \\
novembro/2019 & $7.326 .275,20$ & $7.276 .660,75$ & 4,29 & 4,41 \\
dezembro/2019 & $6.650 .364,30$ & $6.180 .363,17$ & 4,36 & 4,49 \\
janeiro/2020 & $4.282 .103,73$ & $3.204 .569,69$ & 4,24 & 4,30 \\
fevereiro/2020 & $4.566 .487,53$ & $3.692 .155,20$ & 4,40 & 4,59 \\
março/2020 & $7.115 .899,43$ & $6.958 .930,27$ & 4,22 & 4,00 \\
abril/2020 & $7.258 .232,63$ & $7.148 .038,50$ & 4,05 & 4,31 \\
maio/2020 & $7.108 .168,63$ & $7.063 .435,85$ & 4,22 & 3,99 \\
junho/2020 & $7.312 .149,93$ & $7.250 .535,22$ & 4,03 & \\
\hline
\end{tabular}

Nota. Fonte: Elaboração própria com base nos dados da CONAB.

Tabela 4

Quantidade e preço previsto de maçã de Santa Catarina negociada na Ceasa de Curitiba

\begin{tabular}{|c|c|c|c|c|}
\hline \multirow[b]{2}{*}{ Período } & \multicolumn{2}{|c|}{ Quantidade (kg) } & \multicolumn{2}{|c|}{ Preço (kg) } \\
\hline & $\begin{array}{c}\text { Holt-Winter } \\
\text { Aditivo }\end{array}$ & $\begin{array}{c}\text { Holt-Winter } \\
\text { Multiplicativo }\end{array}$ & $\begin{array}{c}\text { Holt-Winter } \\
\text { Aditivo }\end{array}$ & $\begin{array}{c}\text { Holt-Winter } \\
\text { Multiplicativo }\end{array}$ \\
\hline julho/2019 & $26.635 .501,09$ & $27.557 .256,59$ & 3,31 & 3,36 \\
\hline agosto/2019 & $27.818 .479,59$ & $28.638 .640,38$ & 3,42 & 3,49 \\
\hline setembro/2019 & $26.965 .293,59$ & 27.787.959,99 & 3,45 & 3,53 \\
\hline outubro/2019 & $26.697 .768,89$ & $27.526 .731,15$ & 3,54 & 3,66 \\
\hline novembro/2019 & $30.510 .562,29$ & $31.327 .757,33$ & 3,32 & 3,38 \\
\hline dezembro/2019 & $41.949 .768,49$ & 42.633.274,39 & 3,04 & 3,03 \\
\hline janeiro/2020 & $55.997 .028,35$ & $56.882 .153,38$ & 2,91 & 2,81 \\
\hline fevereiro/2020 & $67.033 .508,25$ & $67.951 .781,22$ & 2,96 & 2,88 \\
\hline março/2020 & $73.019 .456,65$ & $73.629 .569,26$ & 3,08 & 3,04 \\
\hline abril/2020 & $55.197 .144,45$ & $55.604 .173,63$ & 3,14 & 3,09 \\
\hline maio/2020 & $41.404 .658,85$ & $41.969 .365,85$ & 3,35 & 3,40 \\
\hline junho/2020 & $31.715 .091,25$ & $32.153 .854,23$ & 3,33 & 3,35 \\
\hline
\end{tabular}

Nota. Fonte: Elaboração própria com base nos dados da CONAB. 
A Cadeia Produtiva da Maçã em São Joaquim-SC sob as Perspectivas: Embeddedness e Formação de Preços e Quantidades Frederico Santos Damasceno, Fabio Piccinini, Ẩngelo Brião Zanela

\section{CONSIDERAÇÕES FINAIS}

Ao buscar aderência entre as proposições teóricas sintetizadas neste trabalho e a atividade econômica promovida pela cadeia produtiva da maçã em São Joaquim-SC concluiu-se que o "embeddedness" (enraizamento) teve papel importante perante as atividades econômicas no município em questão. Pois, além do mecanismo de preços, a interação social de atores individuais e coletivos foi fundamental para produzir a natureza da troca econômica. Especificamente, concluiu-se que as características de "imbricamento" na indústria da maçã em São Joaquim-SC explicam que aquele território desenvolveu-se a partir de uma atividade econômica cujos vínculos sócioculturais entre os participantes de toda a cadeia produtiva mostram-se evidentes. São evidências que são percebidas pelas condições históricas e culturais, pelas características socioeconômicas da região e, até mesmo, pela constatação por parte dos atores incorporados ao processo produtivo de que o clima frio da região é propício à produção da maçã Fuji.

Entre o final dos anos 50 e início dos anos 1970 ocorreram profundas mudanças no ambiente territorial-espacial, oriundas da criação de uma rede de relacionamentos que permitiu disseminar um considerável grau de aprendizado em nível técnico, promovendo transformações nas atividades que antes envolviam poucos trabalhadores, e que, a partir de então, incorporou mão de obra mais qualificada, reestruturando a economia do município de São Joaquim.

Os atores sociais envolvidos na produção de maçã Fuji também entendem que o produto apresenta certas peculiaridades, a exemplo da qualidade superior devido principalmente aos quesitos: formato, coloração e sabor. Tais peculiaridades foram agregadas ao produto a partir de uma ação conjunta que engloba: o trabalho pioneiro dos primeiros cultivadores, pequenos fruticultores que repassavam o velho conhecimento entre os grupos já envolvidos na produção ou aos entrantes, da parcela de imigrantes que contribuiu com pesquisa e mão de obra para o alcance do conhecimento técnico incorporado, pela ação pública por meio das atitudes dos 
A Cadeia Produtiva da Maçã em São Joaquim-SC sob as Perspectivas: Embeddedness e Formação de Preços e Quantidades

Frederico Santos Damasceno, Fabio Piccinini, Ẩngelo Brião Zanela

governantes locais que inseriram instituições aptas à pesquisa e à disseminação dos arranjos empresariais que promoveram um maior dinamismo da atividade econômica.

Ou seja, diante de todo contexto aqui estabelecido, permite-se dizer que a dimensão de "embeddedness" é um fenômeno precursor que possibilitou o avanço da produção de maçã em São Joaquim-SC, região na qual se promoveu um sistema de produção e comércio diferenciados e práticas coletivas que se estenderam por toda cadeia produtiva - cultivo, produção, armazenamento, distribuição e consumo consolidando assim, sua principal atividade econômica e construindo territorialmente esse município. Assim, a valorização das características sociais desse mercado mostra sinais de enraizamento a partir da ação das instituições, dos valores e das características intrínsecos ao produto regionalmente ofertado e à ação dos atores envolvidos.

Por outro lado, análise da variação de preços e quantidades expressam o comportamento de mercado, na medida que mostram o comportamento de variáveis importantes ao longo do tempo. Tomando como base o período 2018-19 a fim de estabelecer uma previsão sobre preços e quantidades para o ano seguinte, 2020, e utilizando os métodos de Holt-Winters, aditivo e multiplicativo, para tal finalidade, observou-se a ocorrência de variações cíclicas que indicam tendências relativas à elevação das quantidades produzidas e quedas nos preços do produto entre os meses de inverno no sul do Brasil, assim como tendências de queda nas quantidades produzidas e elevação dos preços das maçãs nos meses mais quentes do ano na mesma região. As tendências de preços e quantidades, ciclicamente estabelecidos, são influenciadas por fenômenos sazonais, típicos da região de São Joaquim-SC. Os ciclos de alta nos preços e quantidades projetam ganhos oriundos das vendas com exportações e colocação no mercado nacional de um produto de alta qualidade e características intrínsecas. O município como um todo se beneficia já que todo o dinamismo atrelado à cadeia produtiva da maçã gera efeitos multiplicadores nos demais setores produtivos na respectiva localidade. 
A Cadeia Produtiva da Maçã em São Joaquim-SC sob as Perspectivas: Embeddedness e Formação de Preços e Quantidades Frederico Santos Damasceno, Fabio Piccinini, Ấngelo Brião Zanela

Concluiu-se assim, que a produção de maçã em São Joaquim está submersa nas realizações em âmbito institucional, nos valores, características e sabor próprio do produto regionalmente ofertado, valorizando-se assim as características sociais desse mercado, mas que a variação de preço e quantidades mostram tendências que possibilitam explicar por que a produção de maçã consolidou-se como atividade fundamental para o desenvolvimento de São Joaquim-SC.

\section{REFERÊNCIAS}

Barber, B. (1995). All economies are 'embedded': the career of a concept, and beyond. Social Research, Vol.62, No. 2, pp. 387-413.

Brighenti, A., Vieira, H. J., Pasa, M., \& Ciotta, M. N. (2016). A maçã da região de São Joaquim e sua perspectiva histórica, a construção de uma reputação e de uma marca de qualidade. In: Workshop Catarinense de Indicação Geográfica. Joinvile, Santa Catarina, Brasil, 5.

Dickens, P., \& Thrift, N. (1992). The organization of production and the production of organization: why business enterprise matter in the study of geographical industrialization. Institute of British Geographers, Vol. 17, No. 3, pp. 279-291.

Companhia Nacional de Abastecimento - CONAB. Relatórios anuais 2009-2019.

Empresa de Pesquisa Agropecuária e Extensão Rural. (2017). Fruticultura em números. Santa Catarina: EPAGRI.

Emirbayer, M., \& Goodwin, J. (1994). Network analysis, culture and the problem of agency. American Journal of Sociology, Vol. 99, No. 6, pp. 1411-54.

Fleck, A. (2014). Revisitar Polanyi? Notas sobre uma tentativa de atualização crítica. Natal: Revista de Filosofia, Vol. 21, No. 36, pp. 295-316.

Gertler, M. (1997). The invention of regional culture. In: Geographies of Economies. London: Arnold, pp. 47-58, 1997.

Gonçalo, C. R., \& Reyes, J. E. (2012). As redes sociais, uma ferramenta de diagnóstico para estratégias relacionais para a criação do conhecimento em arranjos produtivos locais (APL). Revista Micro e Pequena Empresa. Faculdade campo Limpo Paulista (FACCAMP), Vol. 6, No. 1, pp. 20-37. 
Grabher, G. (1993). The embedded firm: On the socioeconomics of industrial networks. Routlcdge.

Granovetter, Mark. (1973). The strength of weak ties. University of Chicago Press: The American Journal of Sociology, Vol. 78, No. 6, pp. 1360-1380.

(1992). Problems of explanation in economic sociology. In: Networks and organizations: structure, form, and action. Cambridge, MA: Harvard Business School Press, pp. 25-56.

Hess, M. (2004). Spacial relationship? Towards a reconceptualization of embeddedness. Germany: Institute of Economic Geography, University of Munich Germany, Vol.28, No. 2, pp. 165-186.

Machado, N. M. C. (2010). Karl Polanyi e a nova sociologia econômica: notas sobre o conceito de (dis) embeddedness. Lisboa: Revista Crítica de Ciências Sociais, No. 90, pp.71-94.

Marquis, S. (2006). La pomme de São Joaquim, vers une construction collective d'um signe de qualité? Dissertação (Master en Agronomie). Centre National d'Études Agronomiques des Régions Chaudes (CNEARC), Montpellier.

Martin, R. (1994). Economic theory and human geography. In Gregory, D., Martin, R., \& Smith, G. (Orgs.). Human geography. Society, space, and social science, Minneapolis: University of Minnesota Press, pp. 21-53.

Oinas, P. (1997). On the socio-spatial embeddedness of business firms. Erdkunde, Vol. 51, No. 1, pp. 23-32.

Petri, J. L., Leite, G. B., Couto, M., \& Francescatto, P. (2011). Avanços na cultura da macieira no Brasil. Revista Brasileira de Fruticultura [on-line], Vol.33, No. 1, p.48-56. Recuperado de: http://www.scielo.br/scielo.php?pid=S010029452011000500007\&script=sci_abstrct\& tling=pt. Acesso em 8/jul./2018.

Schneider, S. (2009). Território, Ruralidade e Desenvolvimento. In: Velásquez, L. F. \& Medina, J. G. F. (Orgs.). Las Configuraciones de los Territorios Rurales en el Siglo XXI. Bogotá-Colombia: Editorial Pontifícia Universidad Javeriana, Vol. 1, pp. 67-108.

Serviço de Apoio às Micro e Pequenas Empresas - SEBRAE-SC. Recuperado de: < http://www.sebrae-sc.com.br/scemnumero/arquivo/Sao-Joaquim.pdf. > Acesso em: 03/junho/2018. 
Staber, U. (1996). The social embeddedness of industrial district networks. Berlin: De Gruyter, pg.148-74.

Swedberg, R., \& Granovetter, Mark. (1992). Introduction. In Granovetter, M., \& Swedberg, R. (Orgs.). The sociology of economic life, Boulder, CO: Westview Press, pp. 1-26.

Storper, M. (1997). The regional World. Territorial development in a global economy. New York; London: Guilford.

Vale, M. (2000). Uma análise do cluster automóvel em Portugal. Lisboa: Universidade de Lisboa, Finisterra, XXXV, Vol.70, pp. 57-86.

Vasconcellos, G. M. V. (2006). Laços como ativos territoriais: análise das aglomerações produtivas na perspectiva do capital social. (Tese de Doutorado em Administração). Universidade Federal de Lavras, Lavras-MG.

Wasserman, S., \& Faust, K. (1994). Social Network Analysis: Methods and Applications. Cambridge: Cambridge University Press.

Wilkinson, J. (1997). A new paradigm for economic analysis? Economy \& Society, Vol. 26, No. 3, pp. 305-339.

Williamson, O. (1975). Markets and hierarchies: analysis and antitrust implications. New York: The Free.

. (1992). Markets, hierarchies and the modern corporation. Journal of Economic Behavior and Organization, No. 17, pp. 335-352.

. Transaction cost economics and organization theory. In: Smelser, N., \& Sweberg, R. (1994). (Org.). The handbook of economic sociology. Princeton, NJ: Princeton University, pp.77-107. . (1996). The mechanism of governance. New York: The Free.

Data de Submissão: 10/11/2019 Data de Aceite: 10/12/2019 